\title{
Mood as a mediator of the link between child sexual abuse and psychosis
}

\author{
S. Marwaha $\cdot$ P. Bebbington
}

Received: 1 July 2014/ Accepted: 4 October 2014/Published online: 12 October 2014

(c) The Author(s) 2014. This article is published with open access at Springerlink.com

\begin{abstract}
The significance of affective changes in psychosis is increasingly acknowledged, as is the role of early traumatic events. In a previous paper, using data from the English Adult Psychiatric Morbidity Survey 2007 (APMS2007), strong associations between child sexual abuse (CSA) and psychosis were demonstrated, with some evidence of mediation by affect. In the current paper, we subjected the same dataset to formal tests of mediation. For CSA involving sexual intercourse, $38.5 \%$ of the link was mediated, $30.0 \%$ by depression and $8.5 \%$ by anxiety. For all forms of contact abuse, $38.2 \%$ was mediated, $29.1 \%$ by depression and $9.1 \%$ by anxiety.
\end{abstract}

Keywords Psychosis - Sexual abuse - Mediation · Affective disorder · Population survey

\section{Introduction}

The separation of psychotic conditions from disorders regarded as having primary changes in mood is central to psychiatric classification systems. Recently, however, there has been a growing realisation of the significance of affective changes in psychosis. Anxiety and depression are both associated with paranoid ideation and auditory hallucinosis [1]. Conversely, people with anxiety and depressive disorders are more prone to psychotic-like

\section{S. Marwaha}

Division of Mental Health and Wellbeing, Warwick Medical

School, University of Warwick, Coventry CV47AL, UK

P. Bebbington $(\square)$

Division of Psychiatry, University College London,

67-73 Riding House St., London W1W7EJ, UK

e-mail: p.bebbington@ucl.ac.uk experiences [2]. Finally, affective instability is strongly associated with psychosis, with the possibility that this may be responsible for fluctuations in psychotic symptoms [3].

The link between psychotic and affective disorders might arise because they share experiential antecedents. Indeed the affective response to stressful or traumatic events may drive the development of psychotic symptoms. Sexual abuse is a form of trauma that is strongly associated with a wide range of psychiatric disorders [4]. In an earlier paper, Bebbington et al. [5] demonstrated that, in its various forms, childhood sexual abuse is linked to psychosis. Controlling for contemporaneous levels of anxiety and depression (in the week prior to interview) reduced the association, but formal methods for quantifying the degree of putative mediation were not used. In the current paper, we subject the same dataset to a more rigorous procedure for establishing mediation.

\section{Method}

General descriptions of the design and methods used in the 2007 Adult Psychiatric Morbidity Survey have been provided elsewhere [6], and the methods relating specifically to the analysis of sexual abuse are described in more detail by Bebbington et al. [5, 7]. The survey sought to establish a random sample of household residents aged 16 and above, representative of the adult population of England (5,689 of 7,461 participants provided sufficient data for these analyses). First phase interviewing was carried out by experienced non-clinical interviewers; while in a second phase, selected participants were interviewed clinically, in particular with the Schedules for Clinical Assessment in Neuropsychiatry (SCAN, version 2.1) [8]. 
Affect was assessed in relation to the preceding week during phase 1, using the Clinical Interview Schedule (revised) (CIS-R) [9]. This can be used to create overall scores for anxiety (range 0-8) and depressive symptoms (range 0-9). A category of probable psychosis included people diagnosed as such in the second phase, plus participants who did not attend the second phase but met at least two of four screening criteria based on the Psychosis Screening Questionnaire [10], antipsychotic medication use and medical contact with a given diagnosis of psychosis or schizophrenia. A detailed history of sexual abuse was obtained in phase 1 , using confidential computerassisted self-completion to encourage disclosure. In the current analysis, we use information about sexual abuse occurring before the age of 16 years: three levels of abuse were recorded, sexual talk (reported by $10.3 \%$ of the sample), physical molestation (reported by $8.2 \%$ ), and non-consensual sexual intercourse (reported by $1.9 \%$ ). The commonest form, sexual talk, is more subjective than the first two, and is generally less strongly associated with psychiatric outcomes [4]. In the current analysis, we provide data separately for non-consensual sexual intercourse, and for "contact abuse", a category derived by combining intercourse and unwanted sexual touching. Survey data were weighted to take account of survey design and nonresponse, to render the results representative of the English household population.

In the current paper, we used the 'survey' commands in STATA (Version 13 for MAC): these allow for the use of clustered data modified by probability weights, and provide robust estimates of variance. To test the role of affect as a mediator of the relationship linking CSA with psychosis, we applied the Karlson Holm Breen (-khb-) command in Stata. This method of mediation analysis decomposes the total effect of a variable into direct and indirect effects [11] and can be used in logit models. In these analyses, the confounding effects of concomitants on the decomposition were controlled for. These concomitants comprised sex, age, ethnicity, educational qualifications, equivalised household income, and whether the participant had been brought up by both biological parents until 16 years of age. Confidence limits were derived using the delta method of Sobell [12].

\section{Results}

In Table 1, we show in detail mediation analyses incorporating depression and anxiety scores together. We also analysed the separate effects of anxiety and depression, reported in summary. Whether indicated by non-consensual sexual intercourse or by all forms of contact abuse, nearly $40 \%$ of the association between child sexual abuse
Table 1 Mood as a mediator of the link between child sexual abuse and psychosis

\begin{tabular}{lllll}
\hline Effect $\quad$ OR & $\begin{array}{l}\text { Robust standard } \\
\text { error }\end{array}$ & $z$ & $p>z$ & $95 \% \mathrm{CI}$ \\
\hline
\end{tabular}

Depression and anxiety as mediators of the effect of childhood sexual intercourse on psychosis ${ }^{\mathrm{a}}$

$\begin{array}{llllll}\text { Total } & 9.84 & 5.22 & 4.31 & 0.0001 & 3.48-27.85 \\ \text { Direct } & 4.08 & 2.21 & 2.59 & 0.009 & 1.41-11.79 \\ \text { Indirect } & 2.41 & 0.49 & 4.30 & 0.0001 & 1.61-3.61\end{array}$

Depression and anxiety as mediators of the effect of childhood contact abuse on psychosis ${ }^{\mathrm{b}}$

\begin{tabular}{llllll} 
Total & 3.42 & 1.49 & 2.82 & 0.005 & $1.46-8.02$ \\
Direct & 2.14 & 0.94 & 1.73 & 0.083 & $0.91-5.04$ \\
Indirect & 1.60 & 0.16 & 4.74 & 0.0001 & $1.32-1.94$ \\
\hline
\end{tabular}

Data were weighted, and controlled for sex, age, ethnicity, educational qualifications, equivalised household income, and whether the participant had been brought up by both biological parents until 16 years of age

a $38.5 \%$ of the link was mediated, $30.1 \%$ by depression and $8.5 \%$ by anxiety. If depression and anxiety are entered in separate analyses, depression mediates $37.4 \%$ of the link, and anxiety $20.4 \%$

b $38.2 \%$ of the link was mediated, $29.1 \%$ by depression and $9.1 \%$ by anxiety. If depression and anxiety are entered in separate analyses, depression mediates $37.1 \%$ of the link, and anxiety $24.4 \%$

and psychosis was mediated by our measures of affect. In the analysis of contact abuse, the total and indirect effects are highly significant, but the direct effect is so only at trend level, although the odds ratio still exceeded 2. If this is not an issue of statistical power, it implies a predominant role for the mediation effect. In the analyses where depression and anxiety were both entered, depression was responsible for three quarters of the mediation. When anxiety was assessed as a mediator on its own, it was responsible for about a quarter of the link between sexual abuse and psychosis. This suggests that a sizeable amount of the mediation apparently driven by anxiety is best interpreted as being the consequence of the overlap between anxiety and depression. In this respect, the current results are in line with the simpler and less definitive analyses carried out by Bebbington et al. [5]. The results for mediation are remarkably consistent across the two types of sexual abuse that we assessed.

\section{Discussion}

Despite controlling for relevant sociodemographic variables, our analyses provide corroboration for the role of affect in mediating the link between child sexual abuse and psychosis, and suggest that depression may be of more significance in this context than anxiety. We must acknowledge limitations to our use of the data, and these 
are fully discussed by Bebbington et al. [5]. Computerassisted self-completion interviews generally elicit franker responses than face-to-face questioning, and participants in APMS2007 were informed that the interviewer would have no access to their answers. We must also draw attention to a central assumption of our use of measures of current affective state in the mediation analysis. This is that these state measures are adequate indicators of a propensity to dysphoria. Only the latter could stand as a mediator.

Recently, other researchers have found evidence for the mediation by affect of links between childhood abuse and later psychotic symptoms in epidemiological samples [1316]. Our findings support the current targeting of affective responses to stressful experience in cognitive-behavioural approaches to the treatment of psychosis.

Acknowledgments On behalf of both authors, the corresponding author states that neither of us has any conflict of interest. APMS 2007 was carried out in accordance with the ethical standards laid down in the 1964 Declaration of Helsinki and its later amendments. Ethical approval for APMS 2007 was obtained from one of the Research Ethics Committees of the National Research Ethics Service appropriate for non-clinical populations.

\section{Conflict of interest None.}

Open Access This article is distributed under the terms of the Creative Commons Attribution License which permits any use, distribution, and reproduction in any medium, provided the original author(s) and the source are credited.

\section{References}

1. Freeman D, McManus S, Brugha $T$, Meltzer H, Jenkins R, Bebbington P (2011) Concomitants of paranoia in the general population. Psychol Med 41:923-936

2. Varghese D, Scott J, Welham J, Bor W, Najman J, O'Callaghan M, Williams G, McGrath J (2011) Psychotic-like experiences in major depression and anxiety disorders: a population-based survey in young adults. Schizophr Bull 37:389-393

3. Marwaha S, Broome M, Bebbington P, Kuipers E, Freeman D (2014) Mood instability and psychosis: analyses of British national survey data. Schizophr Bull 40:269-277
4. Jonas S, Bebbington PE, McManus S, Meltzer H, Jenkins R, Kuipers E, Cooper C, King M, Brugha T (2011) Sexual abuse and psychiatric disorder in England: results from the 2007 Adult Psychiatric Morbidity Survey. Psychol Med 41:709-720

5. Bebbington PE, Jonas S, Kuipers E, King M, Cooper C, Brugha T, Meltzer H, McManus S, Jenkins R (2011) Sexual abuse and psychosis: data from an English National Survey. Br J Psychiatry 199:29-37

6. Bebbington PE, Jonas S, Brugha T, Meltzer H, Jenkins R, Cooper C, King M, McManus S (2011) Child sexual abuse reported by an English national sample: characteristics and demography. Soc Psychiatry Psychiatr Epidemiol 46:255-262

7. McManus S, Meltzer H, Brugha $T$, Bebbington $P$, Jenkins $R$ (2009) Adult psychiatric morbidity in England, 2007: results of a household survey. NHS Information Centre (http://www.ic.nhs. uk/pubs/psychiatricmorbidity07)

8. World Health Organization (1992) SCAN: schedules for clinical assessment in neuropsychiatry. WHO, Geneva

9. Lewis G, Pelosi AJ, Araya R, Dunn G (1992) Measuring psychiatric disorder in the community: a standardized assessment for use by lay interviewers. Psychol Med 22:465-486

10. Bebbington PE, Nayani T (1995) The psychosis screening questionnaire. Int J Methods Psychiatr Res 5:11-20

11. Breen R, Karlson KB, Holm A (2013) Total, direct, and indirect effects in logit and probit models. Sociol Methods Res 42:164-191

12. Sobel ME (1982) Asymptotic confidence intervals for indirect effects in structural equation models. In: Leinhardt $\mathrm{S}$ (ed) Sociological methodology. American Sociological Association, Washington DC, pp 290-312

13. Fisher HL, Appiah-Kusi E, Grant C (2012) Anxiety and negative self-schemas mediate the association between childhood maltreatment and paranoia. Psychiatry Res 196:323-324

14. Fisher HL, Schreier A, Zammit S, Maughan B, Munafò MR, Lewis G, Wolke D (2013) Pathways between childhood victimization and psychosis-like symptoms in the ALSPAC birth cohort. Schizophr Bull 39:1045-1055

15. Sitko K, Bentall RP, Shevlin M, O'Sullivan N, Sellwood W (2014) Associations between specific psychotic symptoms and specific childhood adversities are mediated by attachment styles: an analysis of the National Comorbidity Survey. Psychiatry Res 30(217):202-209

16. van Nierop M, van Os J, Gunther N, van Zelst C, de Graaf R, ten Have M, van Dorsselaer S, Bak M, Myin-Germeys I, van Winkel $R$ (2014) Does social defeat mediate the association between childhood trauma and psychosis? Evidence from the NEMESIS-2 Study. Acta Psychiatr Scand 129:467-476 